\title{
Chanching the externalizing and internalizing spectrum of personality with self-regultaion therapy
}

\author{
Salvado Amigó. \\ Departament de Personalitat, Avaluació i \\ Tractaments Psicològics \\ Universitat de València \\ Valencia, Spain \\ Salvador.Amigo@uv.es
}

\author{
Joan C. Micó. \\ Intitut Universitari de Matemàtica \\ Multidisciplinar \\ Universitat Politècnica de València \\ Valencia, Spain \\ jmico@mat.upv.es
}

\author{
Antonio Caselles. \\ IASCYS member \\ Departament de Matemàtica Aplicada. \\ Universitat de València \\ Valencia, Spain \\ Antonio.Caselles@uv.es
}

\begin{abstract}
This article presents an integrator model of changes in the externalizing and internalizing factors of personality grouped in the General Factor of Personality (GFP), based on the Unique Trait Personality Theory (UTPT) [1]. This theory proposes that a continuum exists between personality and psychopathology, as well as the existence of a GFP that occupies the apex of the hierarchy of personality, and extends from an impulsiveness-and-aggressiveness pole (externalizing spectrum) to an anxiety-and-introversion pole (internalizing spectrum). With an experimental intra-group design, 30 regular users of stimulant drugs (cocaine and amphetamine) used the Self-Regulation Therapy (SRT). The SRT is a psychological procedure based on classic conditioning and suggestion used to experience a relaxation effect after the first session, and a stimulation effect during the second session. This stimulation is achieved by reproducing, by the SRT, the sensations produced by stimulant drugs. Effects were recorded on format-state scales of personality adjectives and activation, which represented both externalizing and internalizing factors. The results showed that both relaxation and stimulation, by imitating the effects of drugs, brought about short-term changes in both the GFP, and the externalizing and internalizing factors, and also in the predicted direction, i.e., changes in global personality.
\end{abstract}

Keywords-General Factor of Personality; externalizing spectrum; internalizing spectrum; Self-Regulation Therapy; stimulant drugs.

\section{Introduction}

William James [2] had already reported the existence of individual differences in the tendency to express or inhibit impulses.

There is a growing empirical evidence for the co-occurrence of disorders through abuse of drugs and antisocial personality disorders, where impulsiveness would presumably be one of their most important shared elements [3]. Such disorders would be grouped as a psychological super- disorder. Gorenstein and Neuman [4] used the term disinhibitory psychopathology to refer to this superfactor. Later other authors presented an integrator model of the disinhibitory factors, which were grouped by the term Externalizing Spectrum [5,6].

Evidence reveals the existence of an Internalizing Spectrum. Unipolar mood disorders and anxiety disorders are often comorbid, as shown in adolescent [7,8] and adult samples [9]. So disorders like anxiety and depression can be subsumed in this super-factor "that can be defined as the tendency to experience feelings or states that 
are inner-directed and usually accompanied by over-controlled behaviour" [10; p. 1125]. Other authors have also found evidence for the existence of the internalizing super-factor, which would include disorders like major depressive disorder, dysthymia, generalized anxiety disorder, social phobia, specific phobia, agoraphobia, and panic disorder [11-13].

The common cause that links the different disorders of both spectra has been speculated. Some authors assume that these disorders are related with personality [3]. These authors have reviewed studies from which strong correlations between these disinhibitory personality constructs and mental disorders, which involve substance problems and antisocial behavior, have been obtained. These results are consistent with the dimensional conception of personality and psychopathology, which is explicit in many studies and implicit in the Fifth Edition of the Diagnostic and Statistical Manual of Mental Disorders [14]. Thus personality is closely linked to psychopathology $[15,16]$.

In line with the externalizing spectrum, some of the personality factors that are especially related with the disinhibition of impulses are disinhibition [4,17] impulsivity [18-21], sensation-seeking [22], and novelty-seeking [23].

In line with the internalizing spectrum, the personality factors considered particularly basics are Neuroticism [10,24,25], and negative emotionality [5].

An integrator model of these two groups of disorders and personality factors exists, and proposes a single factor to explain complete personality: the General Factor of Personality (GFP), based on the Unique Trait Personality Theory (UTPT) [1]. This theory proposes that a continuum exists between personality and psychopathology, as well as the existence of the GFP, which occupies the apex of the hierarchy of personality, and extends from an impulsivenessand-aggressiveness pole (approach tendency) to an anxiety-and-introversion pole (avoidance tendency). The approach tendency, therefore, groups all the personality factors and disorders of the externalizing spectrum, whereas avoidance tendency groups all the personality factors and disorders of the internalizing spectrum.

The possibility of short-term changes being made in the GFP in response to stimulant substances, like caffeine and methylphenidate, and predicting the result using a dynamic mathematical model have been demonstrated [26-28]. The possibility of training drug users so they can reproduce the effects of stimulating drugs and experience similar effects to those a drug produces has also been demonstrated by the so-called Self-
Regulation Therapy (SRT) procedure [29,30]. This procedure, based on classic conditioning and suggestion, is provided in detail by Amigó [31].

This article presents the procedure and results of an experiment carried out with a group of regular drug users. These subjects used the SRT to experience relaxation during a first session and to experience effects of stimulant drugs (cocaine and amphetamine) during a second session. This is, therefore, an intra-subject experimental design to compare two different effects of the SRT: relaxation and immediate stimulation. For this purpose, several format-state scales of adjectives, filled out by subjects before and after the SRT were used, which assessed the factors that represented both the externalizing spectrum (GFP, extraversion, energetic arousal, sensation-seeking, openness to experience) and the internalizing spectrum (neuroticism, tense arousal, conscience). Several studies have verified that these format-state scales well represent stable personality factors when it comes to studying their short-term modification $[32,33]$.

\section{Methodology}

\section{Participants}

Thirty regular stimulant drug users participated in this study, whose mean age was 26.53 years $(S D=5.36)$, of whom 17 were males (56.7\%) and 13 were females (43.3\%). Sixteen worked (53.3\%) and 14 were students (46.7\%), especially university students.

Table 1 offers the levels of drug use: times and quantity in one's lifetime, times in the last 12 months and times in the last month.

(The section Appendix, after the section References, is devoted to present some tables).

We can see that a high percentage of the participants had tried drugs once in their lifetime: 100\% for cannabis and $96.7 \%$ for cocaine. The drugs they had most widely used in their lifetime were cannabis, followed by cocaine, ecstasy and amphetamine. Drug use in the last 12 months and in the last month showed a higher percentage for cannabis (66.7\% and 56.7\%, respectively), and significantly lower percentages for all the other drugs.

\section{Instruments}

Several personality and activation scales were chosen for being representative of the factors grouped in the externalizing and internalizing spectra. These were format-state scales, which record the variations that certain experimental conditions can immediately cause. These scales were: 
1. The Five-Adjective Scale of the General Factor of Personality (GFP-FAS) [34]. The 5 adjectives are: adventurous, daring, enthusiastic, merry and bored. The GFP-FAS is related positively with Extraversion, Agreeableness and Openness, and negatively with Neuroticism and Conscientiousness. However, it can integrate all basic traits of personality [34]. Two versions of the GFP-FAS were used: trait-format version and state-format version ("Are you like this at the moment?” or “do you feel so at the moment?”). All the participants filled out the state-format version form every 15 minutes to obtain a situational measure of the GFP.

2. The Big Five Personality Adjectives List (BFPAL) [35]. This list is made up of 25 adjectives. A state-format version (“Are you like this at the moment?”) was used. The twenty subjects completed the state-format version every 15 minutes to obtain a situational measure of the BFPAL.

3. List of adjectives from the Sensation-Seeking Scale (SS), selected from the Multiple Affect Adjective Checklist Revised (MAACL-R) [36]. The 132-item MAACL-R provides valid measures of anxiety, depression, hostility, positive affect and sensation seeking. SS is a 12Likert response item scale. Its adjectives are: active, adventurous, aggressive, daring, energetic, enthusiastic, merry, mild, quiet, tame, wild and bored. Two versions were used for the list of adjectives from the Sensation-Seeking Scale: trait format (SS-T) ("Are you like this in general?”) and state format (SS-S) (“Are you like this at the moment?" or "do you feel so at the moment?"). This scale is used in this study because it is a good approach to the GFP.

4. A short form of the Activation-Deactivation Adjective Check List (AD ACL) [37]. This is a multidimensional test of various transitory arousal states. There are five adjectives on each subscale, and each adjective is self-rated on a 4point continuum. Two subscales were chosen for this experiment: energy and tension. The adjectives included in these two subscales were energetic, lively, active, vigorous, and full of pep, and tense, clutched-up, fearful, jittery, and intense.

\section{Procedure and study hypothesis}

An intra-subject experimental design was used to compare the results of applying the SRT during two different sessions. During each session, subjects filled out the scales before and after applying the SRT. During the first session, the SRT was applied to the relaxation state, and it was applied during the second session to achieve strong stimulation. In the latter case, the SRT was addressed to reproduce effects of the stimulant drugs that the subjects normally used, particularly cocaine and amphetamine.

The main hypothesis put forward in this study was that relaxation and stimulation would have effects in the opposite direction, as measured by the different scales used herein. Accordingly, stimulation (reproducing the effects of stimulant drugs with the SRT), unlike relaxation, was expected to increase the score on the scales that represented both the externalizing spectrum (GFP, extraversion, energetic arousal, sensation-seeking and openness to experience) and the internalizing spectrum, which represented activation (neuroticism and tense arousal), and would, in parallel, reduce Conscientiousness. Inverse effects can be expected to be the result of the SRT relaxation session.

\section{Results}

All the subjects participated under the two experimental conditions: relaxation and drug effects reproduction. Two-way repeated measures ANOVAs were used for all the study variables. One factor was the experimental condition with two levels (Relaxation and Reproduction), while the other factor was each state variable (GFP, Big Five, Sensation-Seeking, Arousal) with two levels (before and after each session).

The tables below present the estimated marginal means, the mean differences before and after each session, and for each experimental condition (relaxation vs. stimulation), for those scales on which the interaction between the two factors was significant. This was done in this way in order to verify the hypothesis of this study, i.e., the interaction of the two factors was indeed relevant.

Table 2 provides a summary of the two-way repeated measures ANOVA results for The FiveAdjective Scale of the General Factor of Personality (GFP-FAS).

Table 2. The ANOVA results for The Five-Adjective Scale of the General Factor of Personality (GFP-FAS) (Sig.= significance).

\begin{tabular}{|l|l|c|c|c|}
\hline CONDITION & TIME & $\begin{array}{c}\text { Estimated } \\
\text { marginal } \\
\text { mean }\end{array}$ & $\begin{array}{c}\text { Mean } \\
\text { difference }\end{array}$ & Sig. \\
\hline \multirow{2}{*}{ RELAXATION } & BEFORE & 16.033 & 1.533 & .027 \\
\cline { 2 - 3 } & AFTER & 14.500 & & \\
\hline \multirow{2}{*}{ STIMULATION } & BEFORE & 13.800 & -4.667 & .000 \\
\cline { 2 - 3 } & AFTER & 18.467 & & \\
\hline
\end{tabular}

We can see that there were significant differences for the SRT in the opposite direction depending on the experimental condition, which lowered after the relaxation session and increased after the stimulation session.

Table 3 provides a summary of the two-way repeated measures ANOVA results for The Big Five 
Personality Adjectives List (BFPAL). (See Appendix).

We can see that the results were similar to those obtained for the GFP scale. Thus Extraversion and Neuroticism varied in the opposite direction depending on whether the relaxation or stimulation session was being performed, and they increased with stimulation and reduced with relaxation. Although Conscience was not modified by the relaxation session, it significantly reduced after the stimulation session. No significant interaction effects were observed in the Agreeableness and Openness to Experience factors, so mean differences were not calculated.

Table 4 provides a summary of the two-way repeated measures ANOVA results for the List of adjectives from the Sensation-Seeking Scale (SS).

Table 4. The ANOVA results for the list of adjectives from the Sensation-Seeking Scale (SS). (Sig.= significance).

\begin{tabular}{|l|l|c|c|c|}
\hline \multirow{2}{*}{ CONDITION } & TIME & $\begin{array}{c}\text { Estimated } \\
\text { marginal } \\
\text { mean }\end{array}$ & $\begin{array}{c}\text { Mean } \\
\text { difference }\end{array}$ & Sig. \\
\hline RELAXATION & BEFORE & 25.933 & 8.167 & .000 \\
\cline { 2 - 3 } & AFTER & 27.767 & & \\
\hline \multirow{2}{*}{ STIMULATION } & BEFORE & 31.967 & -11.467 & .000 \\
\cline { 2 - 3 } & AFTER & 43.433 & & \\
\hline
\end{tabular}

The obtained result was similar to that obtained in the previous cases. The relaxation session significantly reduced the Sensation-Seeking score, while this score significantly rose after performing the stimulation session with the SRT.

Table 5 provides a summary of the two-way repeated measures ANOVA results for the Energy and Tension Scales, from a short form of the ActivationDeactivation Adjective Check List (AD ACL). (See Appendix).

Similar results were obtained to those in the previous cases. While the relaxation session significantly reduced both arousal types, the opposite was achieved after reproducing the effects of stimulant drugs with the SRT.

\section{Discussion}

This study verified the possibility of significantly changing personality and arousal factors in the short term by modifying participants' level of activation with the SRT, a procedure based on classic conditioning and suggestion. The intra-group experimental design verified that the relaxation and stimulation produced by the SRT during different sessions had opposite effects, which were measured using the scores of different personality formatstate scales before and after applying the SRT.

These format-state scales were selected to represent the GFP extremes, which we conceptualized herein as the externalizing and internalizing spectra.
Let's remember that the initial hypothesis stated that stimulation with SRT would produce an increased response in the scales that represented both the externalizing spectrum (GFP, extraversion, energetic arousal, sensation-seeking and openness to experience) and the internalizing spectrum, which represented activation (neuroticism and tense arousal), and that Conscientiousness would reduce. Indeed this is what the present study achieved, except for openness to experience, for which neither significant effect of interaction was obtained with the ANOVA, nor was a significant effect of interaction obtained for the Agreeableness dimension. Furthermore, SRT did not influence level of conscience.

All the scores for the other factors were modified in the direction postulated by this study; i.e., stimulation, unlike relaxation, significantly increased the factors grouped in the externalizing spectrum. The opposite was achieved after the relaxation session had taken place. It was noteworthy that two outstanding effects were observed after stimulation, increased neuroticism and reduced conscience, which we now go on to indicate in detail.

Neuroticism has been considered a common dimension to internalizing disorders [10], and even the genetic foundation has been postulated, which relates this dimension with internalizing disorders [38]. This study verified that, as expected, relaxation significantly lowered the Neuroticism score. However, stimulation significantly increased Neuroticism, which also agreed with the hypothesis set out herein because in this case, as with the Tension scale, Neuroticism was considered a type of activation with negative emotionality.

Regarding conscience, several meta-analyses and reviews have concluded that a close relation exists between conscience and externalizing psychopathology (negatively) [39-41]. Change in conscience throughout one's lifetime has been studied. Indeed when conscience starts to increase with age, dependence on alcohol and drug abuse, antisocial conduct and criminal activities lessens [42,43]. However, what the present study attempted to do was to analyze the short-term changes (after one session) in conscience after a relaxation session and a stimulation session. Although relaxation did not influence change in conscience, stimulation significantly lowered the conscience score, which agreed with the general increase noted in the externalizing factors that stimulation with the SRT produced.

In short, we conclude that it is possible to modify the integrated series of externalizing and internalizing personality factors in the short term by using a suggestion and classic conditioning technique like the SRT. If we consider externalizing and internalizing factors to be the two opposite poles of the GFP, we can also conclude that it is possible to change global personality in the short term, which has been previously demonstrated in the above-cited studies [26,27,44]. If it is possible to change global personality in the short term, it is feasible to think 
about the possibility of changing personality in the long term. A dynamic mathematical model exists that predicts the long-term effect on personality of drug use [45].

It is also possible to significantly increase scores on externalizing personality factors by a procedure, the SRT, based on reproducing the effects of stimulating drugs, as well as basic biological mechanisms of personality, as revealed by brain imaging and genetic studies [29]. This result opens up a series of considerable possibilities to apply this procedure to the psychotherapy field and to transform the human being in general.

\section{REFERENCES}

[1] Amigó, S. (2005). La teoría del rasgo único de personalidad. Hacia una teoría unificada del cerebro y la conducta [The Unique Personality Trait Theory. Towards a unified theory of brain and behavior]. Valencia, Spain: Universitat Politècnica de València.

[2] James, W. (1983). The principles of psychology. Cambridge, MA: Harvard University Press. (Original work published 1890).

[3] Sher KJ \& Trull TJ. (1994). Personality and disinhibitory psychopathology: Alcoholism and antisocial personality disorder. Journal of Abnormal Psychology, 103, 92-102.

[4] Gorenstein, E.E. \& Newman, J.P. (1980). Disinhibitory psychopathology: A new perspective and a model for research. Psychological Review, 87, 303-315.

[5] Krueger, R.F., McGue, M. \& Iacono, W.G. (2001). The higher-order structure of common DSM mental disorders: internalization, externalization, and their connections to personality. Personality and Individual Differences, 30, 1245-1259.

[6] Krueger, R.F., Markon, K.E., Patrick, C.J. \& Iacono, W.G. (2005). Externalizing psychopathology in adulthood: A dimensional-spectrum conceptualization and its implications for DSM-V. Journal of Abnormal Psychology, 114, 537-550.

[7] Essau, C.A. (2003). Comorbidity of anxiety disorders in adolescents. Depression and Anxiety, 18, 1-6.

[8] Lewinsohn, P.M., Zinbarg, R., Seeley, J.R., Lewinsohn, M. \& Sack, W.H. (1997). Lifetime comorbidity among anxiety disorders and between anxiety disorders and other mental disorders in adolescents. Journal of Anxiety Disorders, 11, 377-394.

[9] Kessler, R.C., Chiu, W.T., Demler, O. \& Walters, E.E. (2005). Prevalence, severity, and comorbidity of the 12month DSM-IV disorders in the National Comorbidity Survey Replication. Archives of General Psychiatry, 62, 617-627.
[10] Griffith, J.W., Zinbarg, R.E., Craske, M.G., Mineka, S. \& Rose, R.D., et al. (2010). Neuroticism as a common dimension in the internalizing disorders. Psychological Medecine, 40, 1125-1136.

[11] Krueger, R.F. (1999). The structure of common mental disorders. Archives of General Psychiatry, 56, 921-926.

[12] Krueger, R.F. \& Markon, K.E. (2006). Reinterpreting comorbidity: A model-based approach to understanding and classifying psychopathology. Annual Review of Clinical Psychology, 2, 111-133.

[13] McGlinchey, J.B. \& Zimmerman, M. (2007). Examining a dimensional representation of depression and anxiety disorders' comorbidity in psychiatric outpatients with item response modeling. Journal of Abnormal Psychology, 116, 464-474.

[14] Widiger, T.A. \& Samuel, D.B.( 2005). Diagnostic categories or dimensions? A question for the Diagnostic and Statistical Manual of Mental Disorders-Fifth Edition. Journal of Abnormal Psychology, 114, 494- 504.

[15] Watson, D., Clark, L.A. \& Harkness, A.R. (1994). Structures of personality and their relevance to psychopathology. Journal of Abnormal Psychology, 103, 18-31.

[16] Widiger, T.A. \& Smith, G.T. (2008). Personality and psychopathology. In: John, OP.; Robins, RW.; Pervin, LA., editors. Handbook of personality. 3rd Ed. The Guilford Press; New York.

[17] Clark, L.A. \& Watson, D. (1999). Temperament: A new paradigm for trait psychology. In: Pervin, LA.; John, OP., editors. Handbook of personality: Theory and research. 2. New York: Guilford Press, p. 399-423.

[18] Barratt, E.S. (1994). Impulsiveness and aggression. In: Monahan, J.; Steadman, HJ., editors. Violence and mental disorder: Developments in risk assessment. Chicago: University of Chicago Press, p. 61-79.

[19] Dickman, S.J. (1990). Functional and dysfunctional impulsivity: Personality and cognitive correlates. Journal of Personality and Social Psychology, 58, 95-102.

[20] Gray, J.A. (1981). A critique of Eysenck's theory of personality. In: Eysenck, HJ., editor. A model for personality. Berlin: Springer. p. 246-277.

[21] Whiteside, S.P. y Lynam, D. R. (2001). The five factor model and impulsivity: Using a structural model of personality to understand impulsivity. Personality and Individual Differences, 30, 669-689.

[22] Zuckerman, M. \& Kuhlman, D.M. (2000). Personality and risk-taking: Common biosocial factors. Journal of Personality, 68, 999-1029. 
[23] Cloninger, C.R., Svrakic, D.M. \& Przybeck, T.R. (1993). A psychobiological model of temperament and character. Archives of General Psychiatry, 50, 975-990.

[24] Brown, T.A., Chorpita, B.F. \& Barlow, D.H. (1998). Structural relationships among dimensions of the DSM-IV anxiety and mood disorders and dimensions of negative affect, positive affect, and autonomic arousal. Journal of Abnormal Psychology, 107:179-192.

[25] Kotov, R., Watson, D., Robles, J.P. \& Schmidt, N.B. (2007). Personality traits and anxiety symptoms: The multilevel trait predictor model. Behaviour Research and Therapy, 45, 1485-1503.

[26] Amigó S., Caselles A., \& Micó J. C. (2013). The self-regulation therapy to reproduce drug effects: A suggestion technique to change personality and the DRD3 gene expression. International Journal of Clinical and Experimental Hypnosis, 61, 282-304.

[27] Amigó S., Caselles A., Micó J. C., \& García J. M. (2009). Dynamics of the unique trait of personality: Blood's glutamate in response to methylphenidate and conditioning. Revista Internacional de Sistemas, 16, 3540 .

[28] Caselles A., Micó J. C., \& Amigó S. (2011). Dynamics of the general factor of personality in response to a single dose of caffeine. The Spanish Journal of Psychology, 14, 675-692.

[29] Amigo, S. (2016). Sugar pills to experience cocaine and other drug effects: the Self-Regulation Therapy as a placebo without deception. EC Neurology, 3, 320-331.

[30] Amigó, S. \& Ferrández, C. (2015). Experiencing Effects of Cocaine and Speed with Self-Regulation Therapy. The Spanish Journal of Psychology, 18, 1-10.

[31] Amigó, S. (2014). Manual of controlled drug use. Madrid, Spain: Liber Factory.

[32] Micó J. C., Amigó S., \& Caselles A. (2012). Changing the general factor of personality and the c-fos expression with methylphenidate and self-regulation therapy. The Spanish Journal of Psychology, 15, 850-867.

[33] Micó J. C., Amigó S., \& Caselles A. (2014). From the Big Five to the General Factor of Personality: a Dynamic Approach. Spanish Journal of Psychology, 17, $1-18$.

[34] Amigó S., Micó J. C., \& Caselles A. (2009). Five adjectives to explain the whole personality: A brief scale of personality. Revista Internacional de Sistemas, 16, 4143.

[35] Brody N., \& Ehrlichman H. (1998). Personality psychology. The science of individuality. New Jersey, NJ: Prentice Hall, Inc.

[36] Zuckerman, M., Lubin, B., \& Rinck, C. M. (1983). Construction of new scales for the Multiple Affect Adjective Check list. Journal of Psychopathology and Behavioral Assessment, 5, 119-129.

[37] Thayer, R.E. (1987). Problem perception, optimism, and related states as a function of time of the (diurnal rhythm) and moderate exercise: two Arousal Systems in interaction. Motivation and Emotion, 11, 19-36.

[38] Hettema, J.M., Neale, M.C., Myers, J.M., Prescott, C.A. \& Kendler, K.S. (2006). A population-based twin study of the relationship between Neuroticism and Internalizing Disorders. American Journal of Psychiatry, 163, 857-864).

[39] Roberts, B. W., Jackson, J. J., Burger, J., \& Trautwein, U. (2009). Conscientiousness and externalizing psychopathology: Overlap, developmental patterns, and etiology of two related constructs. Development and Psychopathology, 21, 871- 888.

[40] Ruiz, M. A., Pincus, A. L., \& Schinka, J.A. (2008). Externalizing pathology and the five-factor model: A meta-analysis of personality traits associated with antisocial personality disorder, substance use disorder, and their co-occurrence. Journal of Personality Disorders, 22, 365-388.

[41] Saulsman, L. M., \& Page, A. C. (2004). The fivefactor model and personality disorder empirical literature: A meta-analytic review. Clinical Psychology Review, 23, 1055-1085.

[42] Hare, R. D., McPherson, L. M. \& Forth, E. A. (1988). Male psychopaths and their criminal careers. Journal of Consulting and Clinical Psychology, 56, 710714.

[43] Littlefield, A., Sher, K. J., \& Wood, P. K. (2009). Is 'maturing out' of problematic alcohol involvement related to personality change? Journal of Abnormal Psychology, 118, 360-374.

[44] Amigó, S., Caselles, A., \& Micó, J. C. (2008). A dynamic extraversion model: the brain's response to a single dose of a stimulant drug. British Journal of Mathematical and Statistical Psychology, 61, 211-231.

[45] Caselles, A., Micó, J. C., \& Amigó, S. (2010). Cocaine addiction and personality: A mathematical model. British Journal of Mathematical and Statistical Psychology, 63, 449-480. 


\section{Appendix}

Table 1. Frecuencies of drug use. Times and quantity in one's lifetime, in the last 12 months and in the last month.

\begin{tabular}{|c|c|c|c|c|c|c|c|c|c|c|c|c|}
\hline \multirow[t]{2}{*}{ DRUGS } & \multirow{2}{*}{$\begin{array}{c}\text { Some } \\
\text { time in } \\
\text { your life }\end{array}$} & \multicolumn{3}{|c|}{$\begin{array}{l}\text { How often in your } \\
\text { lifetime }\end{array}$} & \multicolumn{4}{|c|}{$\begin{array}{l}\text { How often in the last } 12 \\
\text { months }\end{array}$} & \multicolumn{4}{|c|}{$\begin{array}{l}\text { How often in the last } \\
\text { month }\end{array}$} \\
\hline & & $1-5$ & $6-30$ & $>30$ & 0 & $1-5$ & $6-30$ & $>30$ & 0 & $1-5$ & $6-30$ & $>30$ \\
\hline Cannabis & 100 & 3.3 & 3.3 & 93.3 & 13.3 & 3.3 & 16.7 & 66.7 & 20 & 20 & 3.3 & 56.7 \\
\hline Ecstasy & 90 & 26.7 & 26.7 & 36.7 & 33.3 & 37.7 & 13.3 & 6.7 & 73.3 & 16.7 & - & - \\
\hline Cocaine & 96.7 & 23.3 & 26.7 & 46.7 & 23.3 & 43.3 & 26.7 & 3.3 & 60 & 36.7 & - & - \\
\hline Amphetamine & 80 & 13.3 & 30 & 36.7 & 23.3 & 20 & 30 & 6.7 & 43.3 & 30 & 6.7 & - \\
\hline Hallucinogens & 86.7 & 23.3 & 40 & 23.3 & 40 & 33.3 & 13.3 & - & 76.3 & 13.3 & - & - \\
\hline
\end{tabular}

Table 3. The ANOVA results for The Big Five Personality Adjectives List (BFPAL). (Sig. = significance).

\begin{tabular}{|c|c|c|c|c|c|}
\hline & CONDITION & TIME & $\begin{array}{c}\text { Estimated } \\
\text { marginal } \\
\text { mean }\end{array}$ & $\begin{array}{c}\text { Mean } \\
\text { difference }\end{array}$ & Sig. \\
\hline \multirow{4}{*}{ Extraversion } & \multirow[t]{2}{*}{ RELAXATION } & BEFORE & 15.933 & \multirow[t]{2}{*}{3.767} & \multirow[t]{2}{*}{.000} \\
\hline & & AFTER & 12.167 & & \\
\hline & \multirow[t]{2}{*}{ STIMULATION } & BEFORE & 14.333 & \multirow{2}{*}{-4.067} & \multirow[t]{2}{*}{.000} \\
\hline & & AFTER & 18.400 & & \\
\hline \multirow{4}{*}{ Neuroticism } & \multirow[t]{2}{*}{ RELAXATION } & BEFORE & 9.300 & \multirow[t]{2}{*}{5.667} & \multirow[t]{2}{*}{.000} \\
\hline & & AFTER & 3.633 & & \\
\hline & \multirow{2}{*}{ STIMULATION } & BEFORE & 7.833 & \multirow[t]{2}{*}{-2.400} & \multirow[t]{2}{*}{.014} \\
\hline & & AFTER & 10.233 & & \\
\hline \multirow{4}{*}{ Agreeableness } & \multirow[t]{2}{*}{ RELAXATION } & BEFORE & 15.233 & \multirow[t]{2}{*}{ - } & \multirow[t]{2}{*}{-} \\
\hline & & AFTER & 14.867 & & \\
\hline & \multirow[t]{2}{*}{ STIMULATION } & BEFORE & 13.900 & \multirow[t]{2}{*}{-} & \multirow[t]{2}{*}{-} \\
\hline & & AFTER & 14.967 & & \\
\hline \multirow{4}{*}{ Conscientiousness } & \multirow[t]{2}{*}{ RELAXATION } & BEFORE & 13.300 & \multirow[t]{2}{*}{.967} & \multirow[t]{2}{*}{.226} \\
\hline & & AFTER & 12.333 & & \\
\hline & \multirow[t]{2}{*}{ STIMULATION } & BEFORE & 11.833 & \multirow[t]{2}{*}{3.867} & \multirow[t]{2}{*}{.000} \\
\hline & & AFTER & 7.967 & & \\
\hline \multirow{4}{*}{$\begin{array}{l}\text { Openness to } \\
\text { Experience }\end{array}$} & \multirow[t]{2}{*}{ RELAXATION } & BEFORE & 12.833 & \multirow[t]{2}{*}{-} & \multirow[t]{2}{*}{-} \\
\hline & & AFTER & 14.433 & & \\
\hline & \multirow[t]{2}{*}{ STIMULATION } & BEFORE & 11.100 & \multirow[t]{2}{*}{-} & \multirow[t]{2}{*}{-} \\
\hline & & AFTER & 12.233 & & \\
\hline
\end{tabular}

Table 5. The ANOVA results for the Energy and Tension Scales. (Sig. = significance).

\begin{tabular}{|c|c|c|c|c|c|}
\hline & CONDITION & TIME & $\begin{array}{c}\text { Estimated } \\
\text { marginal } \\
\text { mean }\end{array}$ & $\begin{array}{c}\text { Mean } \\
\text { difference }\end{array}$ & Sig. \\
\hline \multirow{4}{*}{ ENERGY } & \multirow[t]{2}{*}{ RELAXATION } & BEFORE & 13.200 & \multirow[t]{2}{*}{3.500} & \multirow[t]{2}{*}{.000} \\
\hline & & AFTER & 9.700 & & \\
\hline & \multirow[t]{2}{*}{ STIMULATION } & BEFORE & 12.033 & \multirow[t]{2}{*}{-4.400} & \multirow[t]{2}{*}{.000} \\
\hline & & AFTER & 16.433 & & \\
\hline \multirow{4}{*}{ TENSION } & \multirow[t]{2}{*}{ RELAXATION } & BEFORE & 8.700 & \multirow[t]{2}{*}{6.033} & \multirow[t]{2}{*}{.000} \\
\hline & & AFTER & 2.667 & & \\
\hline & \multirow[t]{2}{*}{ STIMULATION } & BEFORE & 7.733 & \multirow[t]{2}{*}{-5.500} & \multirow[t]{2}{*}{.000} \\
\hline & & AFTER & 13.233 & & \\
\hline
\end{tabular}

